\title{
Therapeutic endoscopy practice at a resource-limited setup: experience from a GI center in Addis Ababa, Ethiopia
}

\author{
Abate Bane \\ Division of Gastroenterology, Department of Internal Medicine, Addis Ababa University \\ Rabia Ahmed \\ Adera Medical Center \\ Amir Sultan Seid ( $\square$ amirs08444@gmail.com ) \\ Division of Gastroenterology, Department of Internal Medicine, Addis Ababa University
}

\section{Research Article}

\section{Keywords:}

Posted Date: January 21st, 2022

DOI: https://doi.org/10.21203/rs.3.rs-1258446/v1

License: (c) (i) This work is licensed under a Creative Commons Attribution 4.0 International License. Read Full License 


\section{Abstract}

\section{Background}

Endoscopic evaluation has a diagnostic and therapeutic component. With the advent of technology, many gastrointestinal problems requiring surgical intervention can now be managed endoscopically. In most resource-limited setups the practice of therapeutic endoscopy is scarce and services usually provide diagnostic endoscopic examination only.

\section{Methods}

An 8-year retrospective study was done to assess the pattern and practice of therapeutic endoscopy in patients who underwent therapeutic endoscopic procedures at Adera Medical Center, Addis Ababa, Ethiopia. The socioeconomic, clinical, and endoscopic data of the patients were collected and analyzed.

\section{Results}

During the study period, a total of 27,283 endoscopies and colonoscopies were performed at the center, of whom 1769 patients had therapeutic procedures. The mean age of the patients was $40.95(15.5)$, and the majority $(75.2 \%)$ of the patients were males. Therapeutic procedures included esophageal variceal ligation (69.2\%), sclerotherapy (8.5\%), polypectomy (6.8\%), hemorrhoid banding (5.8\%), achalasia and stricture dilatation (7.1\%), endoscopic foreign body removal (1.7\%), adrenaline injection ( $0.7 \%)$, and hemoclip application ( $0.1 \%)$. Immediate hemostasis was achieved through endoscopic intervention in all patients that presented with upper gastrointestinal bleeding. Achalasia and stricture dilatations were done with immediate post-procedural symptomatic relief in $100 \%$ and $95.56 \%$ of the patients, respectively. $96.67 \%$ of the patients with GIT foreign body impaction and patients with polyps were treated endoscopically without the need for surgical intervention.

\section{Conclusion}

In a resource-limited setup like Ethiopia, the provision of therapeutic endoscopic services can help in the management of a variety of gastrointestinal problems. Efforts geared towards the provision of therapeutic endoscopic services help alleviate multitudes of life-threatening problems as evidenced in this study.

\section{Background}

Diagnostic and therapeutic endoscopy has rapidly advanced over the past 40 years and has become an integral part of clinical gastroenterology. The utilization of endoscopy for diagnostic evaluation, screening, and intervention has markedly increased over the last two decades(1).

Endoscopy offers a minimally invasive method to diagnose and treat gastrointestinal pathologies(2).

In developed countries, endoscopies are utilized to perform advanced and complex procedures such as surgical resection of intraluminal tumors, endoscopic ultrasound-guided fine-needle aspirations, biliary interventions, treatment of bile duct strictures, removal of bile duct stones, pancreatic interventions, and more $(3,4)$. Surveys, on the other hand, revealed that many African countries have a scarcity of GI endoscopy centers, a shortage of endoscopists with advanced endoscopy training, and a lack of endoscopes, accessories, and basic infrastructure(5). A recent study conducted in East Africa showed that Endoscopy capacity is severely limited in eastern sub-Saharan Africa, despite a high burden of gastrointestinal disease(6). In Ethiopia, few medical facilities offer endoscopy, and even fewer provide endoscopic interventions. Furthermore, most of these facilities are located in the capital, Addis Ababa.

Upper gastrointestinal bleeding (UGIB) is a common cause of emergency hospital admissions with significant associated morbidity, mortality, and health care $\operatorname{cost}(7,8)$. Fortunately, endoscopic therapies like epinephrine or sclerosant injection; heater probe or argon plasma coagulation for bleeding ulcers; and endoclips or endoscopic variceal banding have become effective in controlling UGIB. These reduce the risk of rebleeding, the need for blood transfusions, the requirement for surgery, as well as associated mortality and morbidity(9).

Modern endoscopy can also be used to remove foreign bodies like coins, bone pieces, metal pieces, impacted food pieces, sharp and long objects, button batteries, magnets, and other objects from the GIT. Food (typically meat) bolus impaction above a preexisting esophageal stricture or ring is by far the most common cause of esophageal foreign body obstruction in adults. However, children and adolescents, or patients with psychiatric illness and abusers of illicit drugs or alcohol are at a higher risk of ingesting foreign objects like coins and metal pieces (10).

Any benign process that obstructs the esophagus or stomach, or that induces inflammatory or fibrotic changes in the esophagus, stomach or intestine can result in esophageal strictures and gastric outlet obstruction. Inflammatory or fibrotic benign strictures of the GI tract can result in dysphagia, malnutrition, aspiration, and pain (11). The mainstay of such benign GIT strictures treatment is endoscopic dilation (12). Endoscopic dilatation is also used to provide temporary symptomatic relief in patients with achalasia who present with dysphagia and regurgitation (13). 
Endoscopic polypectomy is another efficacious intervention in reducing the risk of colon cancer development by interrupting the adenoma to carcinoma progression (14). Another common condition treated using various endoscopic approaches is hemorrhoid. The best technique adopted for alternative and non-surgical treatment for an intermediate grade (II and III) hemorrhoidal disease is rubber band ligation (15). Although there are many studies on the trends of endoscopic diagnosis in Ethiopia, there is no data on endoscopic interventions.

\section{Objective}

This study aims to assess therapeutic endoscopy practice and evaluate its efficacy and outcome at the center during the study period. The study tries to show the feasibility and value of therapeutic endoscopy in a Sub-Saharan African setup.

\section{Methods}

This is a retrospective study on endoscopic therapeutic interventions performed at Adera Medical Center over 8 years, from October 2013 to September 2021.Adera Medical Center is a large facility engaged in the provision of gastrointestinal care in Ethiopia. It is a leading endoscopic center in the country had been offering diagnostic and therapeutic endoscopy as a pioneer in Addis Ababa since 2008. It is a large private referral center for patients requiring therapeutic interventions across Addis Ababa and beyond.

In this audit, data regarding the patients' socio-demographic status, indication for the procedure, clinical diagnosis, endoscopic diagnosis, and type of procedure was collected from the patient registry and inserted into a structured questionnaire form. Informed written consent was obtained for each patient and/ or attendant, endoscopic interventions were performed by qualified senior gastroenterologists working at the center. For the purposes of the study, procedures which are primarly aimed at delivering endoscopic therapy were defined as therapeutic procedures. The collected data was entered and analyzed using SPSS, version 24 software ( Chicago, Illinois). Waiver of consent to use endoscopic registry data as well as to conduct the study was provided by the governing ethical body of Adera Medical Center.

\section{Results}

A total of 27,283 patients had undergone Esophagogastroduodenoscopy (EGD) and colonoscopy examination at Adera Medical Center during the study period. Amongst these, 1769 patients had a therapeutic endoscopic procedure. The mean age and standard deviation of the patients were 40.95 \pm 15.5. 1330 patients (75.2\%) were males while 439 (24.8\%) were females. Most patients were in the age ranges of 25-34 and $35-44$ accounting for $24.4 \%$ and $23.2 \%$, of the patients, respectively.

Most of the patients $(880,49.7 \%)$ were from Addis Ababa, while, others were from the regions including Oromia (352, 19.9\%), Amhara (153, 8.7\%), SNNPR (107, 6\%), Somali region (71, 4\%), Harar (64, 3.6\%), Afar (39, 2.2\%), Tigray (26, 1.5\%) and Benishangul (9, 0.5\%). Others were from foreign countries such as Somalia, Djibouti, India, South Sudan, Russia, USA, Nigeria, Ghana, Mali, and Italy (64, 3.6\%).

Most of the patients $(76.42 \%)$ had a therapeutic intervention for upper gastrointestinal bleeding. Among these patients, $77.1 \%$ were male, while only $22.9 \%$ of the patients were females. Most $(90.6 \%)$ were treated with endoscopic variceal band ligation (EVL). Others were treated with sclerotherapy (8.4\%), adrenalin injection (0.9\%), and hemoclip application (0.1\%). (Table 1 and Figure 1 ) 
Table 1

Age, sex, and Address of patients that underwent an intervention at Adera Medical Center, October 2013- September 2021

\begin{tabular}{|c|c|c|c|c|c|c|c|c|c|c|c|c|c|c|c|c|c|}
\hline \multirow{4}{*}{ Age } & \multirow{4}{*}{ Mean (SD) } & \multicolumn{2}{|c|}{ EVL done } & \multicolumn{2}{|c|}{ Polypectomy } & \multicolumn{2}{|c|}{$\begin{array}{l}\text { Foreign } \\
\text { body } \\
\text { removal }\end{array}$} & \multicolumn{2}{|c|}{ Sclerotherapy } & \multicolumn{2}{|c|}{$\begin{array}{l}\text { Adrenalin } \\
\text { injection }\end{array}$} & \multicolumn{2}{|c|}{$\begin{array}{l}\text { Endoscopic } \\
\text { dilatation }\end{array}$} & \multicolumn{2}{|c|}{$\begin{array}{l}\text { Hemorrhoid } \\
\text { Banding }\end{array}$} & \multicolumn{2}{|c|}{ Hemoclip } \\
\hline & & \multirow{2}{*}{\multicolumn{2}{|c|}{$\begin{array}{l}42.06 \\
(14.15)\end{array}$}} & \multirow{2}{*}{\multicolumn{2}{|c|}{$\begin{array}{l}37.77 \\
(24.14)\end{array}$}} & \multirow{2}{*}{\multicolumn{2}{|c|}{$\begin{array}{l}21.33 \\
(17.13)\end{array}$}} & \multirow{2}{*}{\multicolumn{2}{|c|}{$\begin{array}{l}41.33 \\
(14.78)\end{array}$}} & \multirow{2}{*}{\multicolumn{2}{|c|}{$\begin{array}{l}46.83 \\
(16.08)\end{array}$}} & \multirow{2}{*}{\multicolumn{2}{|c|}{$\begin{array}{l}37.4 \\
(15.42)\end{array}$}} & \multirow{2}{*}{\multicolumn{2}{|c|}{$\begin{array}{l}40.67 \\
(13.6)\end{array}$}} & \multirow{2}{*}{\multicolumn{2}{|c|}{51}} \\
\hline & & & & & & & & & & & & & & & & & \\
\hline & & $\mathrm{n}$ & $\%$ & $\mathrm{n}$ & $\%$ & $\mathrm{n}$ & $\%$ & $\mathrm{n}$ & $\%$ & $\mathrm{n}$ & $\%$ & $\mathrm{n}$ & $\%$ & $\mathrm{n}$ & $\%$ & $\mathrm{n}$ & $\%$ \\
\hline \multirow[t]{2}{*}{ Sex } & Female & 284 & 16.1 & 42 & 2.4 & 13 & 0.7 & 30 & 1.7 & 1 & 0.06 & 56 & 3.2 & 13 & 0.7 & 0 & 0 \\
\hline & Male & 941 & 53.2 & 79 & 4.5 & 17 & 1 & 120 & 6.8 & 11 & 0.6 & 71 & 4.1 & 90 & 5.1 & 1 & 0.06 \\
\hline \multirow[t]{10}{*}{ Address } & AA & 561 & 31.7 & 87 & 4.9 & 23 & 1.3 & 75 & 4.2 & 9 & 0.5 & 57 & 3.2 & 68 & 3.8 & 0 & 0 \\
\hline & Oromia & 248 & 14 & 20 & 1.1 & 3 & 0.2 & 32 & 1.8 & 2 & 0.1 & 30 & 1.7 & 16 & 0.9 & 1 & 0.06 \\
\hline & Amhara & 119 & 6.7 & 2 & 0.1 & 1 & 0.06 & 18 & 1 & 0 & 0 & 6 & 0.3 & 7 & 0.4 & 0 & 0 \\
\hline & SNNPR & 79 & 4.5 & 3 & 0.2 & 0 & 0 & 11 & 0.6 & 0 & 0 & 9 & 0.5 & 5 & 0.3 & 0 & 0 \\
\hline & Tigray & 20 & 1.1 & 1 & 0.06 & 0 & 0 & 1 & 0.06 & 0 & 0 & 2 & 0.1 & 2 & 0.1 & 0 & 0 \\
\hline & Afar & 36 & 2 & 0 & 0 & 1 & 0.06 & 2 & 0.1 & 0 & 0 & 0 & 0 & 0 & 0 & 0 & 0 \\
\hline & Somali & 55 & 3.1 & 2 & 0.1 & 1 & 0.06 & 3 & 0.2 & 0 & 0 & 9 & 0.5 & 1 & 0.06 & 0 & 0 \\
\hline & Benishangul & 8 & 0.5 & 0 & 0 & 0 & 0 & 1 & 0.06 & 0 & 0 & 0 & 0 & 0 & 0 & 0 & 0 \\
\hline & Harar & 48 & 2.7 & 3 & 0.2 & 0 & 0 & 5 & 0.3 & 0 & 0 & 4 & 0.2 & 4 & 0.2 & 0 & 0 \\
\hline & $\begin{array}{l}\text { Foreign } \\
\text { county }\end{array}$ & 47 & 2.7 & 3 & 0.2 & 1 & 0.06 & 2 & 0.1 & 1 & 0.06 & 10 & 0.6 & 0 & 0 & 0 & 0 \\
\hline
\end{tabular}

\section{[Table 1]}

\section{[Figure 1]}

Patients with actively bleeding esophageal varices (348) were treated with EVL (87.1\%) and sclerotherapy (12.9\%). Among patients with nonbleeding esophageal varices (964), most (95.4\%) were treated with EVL, while only (4.6\%) were treated with sclerotherapy. Patients with bleeding ulcers were primarily treated with adrenalin injection and hemoclip. (Figure 2)

\section{[ Figure 2]}

Polypectomy was performed on $121(6.8 \%)$ patients. $33(27.3 \%)$ of the patients who had polypectomy were below the age of 15 , while others were in the age group $35-44$ (17.4\%), 55-64 (15.7\%), 45-54 (13.2\%), and 65-74 (10.7\%). The male to female ratio was $1.88: 1.69$ (57\%) of the polyps were removed from the rectum. Other polyps were resected from the left colon (14\%), sigmoid (10.7\%), right colon ( $8.3 \%)$, transverse colon (4.1\%), antrum (3.3\%), fundus ( $0.8 \%)$, recto-sigmoid $(0.8 \%)$ and multiple sites in the colon $(0.8 \%)$. Histopathological examination revealed that all polyps were benign and not harboring in situ carcinoma. [Figure 3]

Endoscopic dilation was done for 7.1\% (127) patients. Among these patients, 82(4.6\%) were treated for achalasia while $45(2.5 \%)$ were treated for benign strictures (esophageal stricture $(39,86.7 \%)$, duodenal stricture $(4,8.9 \%)$, gastroesophageal junction stricture $(1,2.2 \%) \&$ anal stricture $(1$, $2.2 \%$ ) also underwent dilation).(Figure 4)

\section{[Figure 4]}

Another therapeutic intervention performed was foreign body removal from the GI tract of patients, constituting $1.7 \%$ of the participants. Most (46.7\%) of these patients were under the age of 15 . The most (36.3\%) common foreign body extracted was bone piece followed by coin (33.3\%), food bolus (13.3\%), metal piece (6.7\%), plastic (3.3\%), Hijab pin (3.3\%), and denture (3.3\%). Swallowed coins were extracted from kids below the age of 15 . While bone piece and food bolus stuck was common among young adults aged $25-44$. Most $(8,26.7 \%)$ of these patients were students. (Figure 5, and 6)

\section{[Figure 5, and 6]}

Hemorrhoids were managed for 139 participants. Of these, $87.1 \%$ were males and only $12.9 \%$ were females. Most (75.5\%) of these patients were between the ages of 25-54 years. Three quarters of them had hemorrhoid banding as therapy while $25 \%$ were treated with sclerotherapy. 
Endoscopic interventions performed had favorable outcomes and the need for surgical intervention was exceedingly rare. Hemostasis was achieved in all the patients with actively bleeding lesions. All of the patients reported symptomatic relief in the immediate post-procedural period after achalasia dilation. Ninety-six percent of the patients with esophageal stricture had improvement of symptoms after dilation. Only one patient required surgical removal of a deeply embedded bone piece in the esophageal wall after diagnosis was delayed for 2 weeks.

\section{Discussion}

The present study tried to look at the practice of therapeutic endoscopy at a large medical center in Addis Ababa, Ethiopia. A total of 1769 patients underwent therapeutic procedures over 8 years. The majority (76.4\%) of the patients in this study got endoscopic treatment for upper gastrointestinal disease. Of these patients, $97 \%$ of the patients were treated for esophageal varices. While $1.8 \%$ of the patients were treated for fundal varices and only $1.1 \%$ of the patients were treated for bleeding duodenal ulcers. This is similar to a recent study in Ethiopia at St. Paul's Millenium Medical College in Addis Ababa, which reported that the most common cause of upper gastrointestinal bleeding was esophageal varices (16). However, studies done in the last two decades showed that the most common cause of UGIB in Ethiopia was duodenal ulcer (17, 18). This change in the etiology of UGIB can be attributed to the introduction of the appropriate use of $\mathrm{H}$. pylori eradication therapy, as well as knowledge and awareness of the transmission dynamics of $\mathrm{H}$. pylori (19). Similarly, multiple recent studies on upper gastrointestinal bleeding conducted in several African countries show that the most common cause of UGIB is esophageal varicies(20-23).

Most of the patients treated for UGIB were males in this study with a male to female ratio of 3.4:1. Similarly, multiple studies conducted in Ethiopia and other countries, showed male predominance among patients presenting with UGIB $(7,16,24)$. This could be as a result of the disproportional predisposition of males to etiological factors that influence UGIB such as gastritis, PUD, and liver cirrhosis caused by viral hepatitis and alcohol abuse (21).

Published papers show that surgery was used to treat portal hypertension with bleeding esophageal varices in Ethiopia as recently as 2005 (25). EVL was started in Ethiopia in 2008 at the study center. In this study, 90 \% $\mathrm{f}$ the patients with UGIB were treated with EVL, similar to a study from Nairobi, Kenya (26). EVL and sclerotherapy were both done for patients with esophageal varices to control actively bleeding lesions and/ or as prophylaxis for bleeding. Some studies show that both sclerotherapy and band ligation are effective in acute hemostasis of bleeding esophageal varices $(27,28)$. While other studies show that variceal band ligation is preferred due to its superior safety profile and shorter procedure time $(27)$. Band ligation has a significantly lower incidence of stricture formation and ulcer bleeding compared to sclerotherapy. Nonetheless, most complications can also be managed with endoscopic interventions (29). On the other hand, other studies show that combined variceal ligation and sclerotherapy had less rebleeding rates and recurrence at six months and less chest pain and was more cost-effective compared to endoscopic variceal ligation alone in the treatment of gastroesophageal varices (30).

Upper gastrointestinal bleeding that cannot be controlled by a minimally invasive endoscopic procedure requires surgical intervention (31). However, in this study EVL and sclerotherapy were successful, and none of the patients required emergency surgical intervention for upper gastrointestinal bleeding. Similar to this study, a study conducted in Morocco showed a high rate of primary hemostasis achieved through endoscopic intervention in patients with upper gastrointestinal bleeding with 96.5 percent of patients being successfully managed (32).

Colonoscopic removal of polyps is shown to have a marked reduction in the rate of and mortality and morbidity associated with colorectal cancer (33-35). Polyps were removed using snares from the rectum (57\%), colon (37.9\%), gastric (4.1\%), and rectosigmoid area (0.8\%) at our center. Large colonic lesions could also be removed by endoscopic submucosal dissection (ESD) or endoscopic mucosal resection (EMR), with high success rates and acceptably low complications, reducing the need for surgery (35). However, the practice of such procedures in Ethiopia is limited and most patients end up requiring surgery.

Although, surgical procedures are done for gastrointestinal strictures are potentially curative, they are associated with high rates of morbidity and mortality. Several non-surgical, minimally invasive interventional endoscopic options are available to treat benign strictures of the esophagus and gastric outlet. These procedures include balloon dilation, temporary stent placement, intralesional steroid injection, and incisional therapy (36). At the medical center where the study was conducted, esophageal strictures are treated with balloon dilatation, followed by steroid injection, and temporary stenting with a success rate of $95.56 \%$. A study done in Egypt on post corrosive esophageal strictures showed a less (78\%) success rate than our study (37). Another study showed a primary efficacy of $98.8 \%$ among children with esophageal strictures (11). Endoscopic esophageal stricture dilatation is also safe \& effective in children (11). In this study, $15.6 \%$ of the patients with esophageal stricture dilatation were below the age of 15 . Most of the studies showed an efficacy rate of stricture dilatation ranging between 90 and $100 \%{ }^{12}$. Comparably, $95.56 \%$ of our patients that had endoscopic stricture dilatation reported symptomatic improvement.

Achalasia is most of the time treated surgically in Ethiopia (38). Definitive therapeutic options offered to patients vary, depending on access, resources, and expertise, and include pneumatic dilation (PD), laparoscopic Heller's myotomy (LHM), or per-oral endoscopic myotomy (POEM). LHM and POEM have been found superior to PD in terms of success (39). A recent study showed that $46 \%$ of patients treated with pneumatic dilation required repeat dilatation, whereas only $8 \%$ of patients treated with POEM required further treatment after 2 years (40). However, these therapeutic interventions are not available in Ethiopia,and patients are usually treated surgically, open transthoracic myotomy. Patients with

Page 5/12 
achalasia who defer surgical treatment had endoscopic dilatation done for temporary symptomatic relief and showed improvement immediately after dilation, but the recurrence rate was $50 \%$ requiring surgical myotomy.

About $80-90 \%$ of the ingested non- sharp foreign bodies pass spontaneously through the gastrointestinal tract without complications, but in $10-$ $20 \%$ of the cases, an endoscopic intervention is deemed necessary (41). Technological advancements in endoscopy have made it possible and safe for the extraction of GIT foreign bodies via endoscopy (42). Flexible Endoscopy is a very safe and efficient method of timely diagnosis and removal of ingested FBs in children and adults and it is the therapeutic method of choice for relieving food impaction and removing true foreign bodies with a success rate of over $95 \%$ and with minimal complications $(41,43)$. In our center, removal of swallowed foreign bodies was completed in $96.67 \%$ of the patients while one patient required surgical intervention due to prolonged impaction, and the bone piece was embedded in the esophageal mucosa. When endoscopic removal is challenging surgical intervention is needed to remove foreign bodies (44). Therefore, our patient was treated surgically. Unfortunately, he developed post-operative stricture, which was successfully dilated endoscopically. In this study, coins were extracted from children under the age of 15 similar to studies that revealed the most common ingested foreign body in children are coins ( 10,45 , 46)

From published studies, endoscopic band ligation has more success and is more cost-effective in treating patients with hemorrhoids as well when compared to sclerotherapy and hemorrhoidectomy $(5,47)$. Most $(74.1 \%)$ of our patients were also treated with band ligation while only $25.6 \%$ of the patients were treated with sclerotherapy for hemorrhoids.

The strength of our study is that it is the first study in Ethiopia and one of the few in SubSaharan Africa, that tried to look into the practice of therapeutic endoscopy. Most previous studies have looked into clinical problems as well as the prevalence of certain conditions in a given population. In addition, the evidence base for the practice of such procedures is needed to justify investment in the field. By showing the practice and the outcome, our study aims to fill the gap in the available literature regarding therapeutic intervention practice in resource-limited setups, primarily in Sub-Saharan Africa. Stakeholder engagement, as well as investment in the field, are required to improve the practice of therapeutic procedures, as most of the accessories employed in these procedures require significant resources and manpower training.

Our study does have limitations too. The main limitation is that our study is retrospective in design and maintaining homogeneity interms of study variables is difficult. In addition, the important clinical, as well as laboratory profile of patients, was not consistently available to provide an overall better picture of findings. The other limitation of our study is that we tried to look into the practice of therapeutic endoscopy in general and details of some interventions were not assessed in depth. Some of the interventions reported require an in-depth analysis of certain parameters which is difficult to confine in this one report; however, the general description of findings would provide a stepping ground for further research in the area. Furthermore, practices of more advanced procedures like EUS and ERCP were not assessed in our study, as these procedures are not widely available hitherto in Ethiopia.

\section{Conclusion}

Interventional endoscopy is a minimally invasive, effective, and cost-efficient treatment for patients with gastrointestinal tract diseases such as upper gastrointestinal bleeding, strictures, achalasia, polyps, hemorrhoids, and GIT foreign body removal. Despite this, endoscopic interventions are scarce due to limited resources, inadequately equipped institutions, and a scarcity of skilled endoscopists in Ethiopia. Hence providing more endoscopy access and training gastroenterologist and endoscopists is recommended. Furthermore, it is essential to incorporate more advanced endoscopic technologies into our medical practice to provide patients with the best care possible.

\section{Declarations}

\section{Ethical Statements -}

Protocol ethical clearance received from Adera Medical Center, Medical services administration. Written informed consent was obtained from participants before undergoing procedure. Waiver of consent to use registery data for the study was obtained from Medical Services administration of Adera Medical Center. All methods were performed in accordance with the relevant guidelines and regulations.

\section{Consent for publication -}

Consent obtained to use endoscopic images from patients who were depicted in the images of the manuscript. All patient informations are deidentified.

Availability of Data \& Materials - The datasets used and/or analyzed during the current study available from the corresponding author on reasonable request.

\section{Competing Interest -}

None 


\section{Funding -}

No funding to declare

\section{Authors Contribution -}

AB conceptually designed the study, drafted the research proposal. RA oversaw data collection and analysis and did manuscript writing. AS refined data analysis did an additional literature review, and edited the manuscript. All authors reviewed the manuscript.

\section{Acknowledgements -}

Authors want to thank the Adera Medical Center staff for the kind support.

\section{References}

1. Nabh A, Sherid M, Spurr C, Sridhar S. Diagnostic Endoscopy. Endoscopy of GI Tract [Internet]. 2013 Mar 13 [cited 2022 Jan 4]; Available from: https://www.intechopen.com/chapters/43598

2. Nguyen VX, li Nguyen VT, Nguyen CC. Appropriate use of endoscopy in the diagnosis and treatment of gastrointestinal diseases: up-to-date indications for primary care providers. International journal of general medicine [Internet]. 2010 Apr [cited 2022 Jan 4];3(4):345-57. Available from: https://pubmed.ncbi.nlm.nih.gov/21116340/

3. https://www.dovepress.com/endoscopic-or-surgical-resection-for-patients-with-2ndash5cm-gastric-g-peer-reviewed-fulltext-article-CMAR

4. Katanuma A, Hayashi T, Kin T, Toyonaga H, Honta S, Chikugo K, et al. Interventional endoscopic ultrasonography in patients with surgically altered anatomy: Techniques and literature review. Digestive Endoscopy [Internet]. 2020 Jan 1 [cited 2022 Jan 4];32(2):263-74. Available from: https://onlinelibrary.wiley.com/doi/full/10.1111/den.13567

5. Cesare Hassan A, Aabakken L, Ebigbo A, Gásdal Karstensen J, Guy C, Dinis-Ribeiro M, et al. Partnership with African Countries: European Society of Gastrointestinal Endoscopy (ESGE) - Position Statement. Endoscopy International Open [Internet]. 2018 Oct 8 [cited 2022 Jan 4];06(10):E1247-55. Available from: http://www.thieme-connect.com/products/ejournals/html/10.1055/a-0677-2026

6. Mwachiro M, Topazian HM, Kayamba V, Mulima G, Ogutu E, Erkie M, et al. Gastrointestinal endoscopy capacity in Eastern Africa. Endoscopy International Open. $2021 \mathrm{Nov}$;09(11):E1827-36.

7. Masoodi M, Saberifiroozi M. Etiology and Outcome of Acute Gastrointestinal Bleeding in Iran:A Review Article. Middle East Journal of Digestive Diseases [Internet]. 2012 Oct [cited 2022 Jan 4];4(4):193. Available from: /pmc/articles/PMC3990128/

8. Alatise Ol, Aderibigbe AS, Adisa AO, Adekanle O, Agbakwuru AE, Arigbabu AO. Management of overt upper gastrointestinal bleeding in a low resource setting: A real world report from Nigeria. BMC Gastroenterology [Internet]. 2014 Dec 10 [cited 2022 Jan 4];14(1):1-9. Available from: https://bmcgastroenterol.biomedcentral.com/articles/10.1186/s12876-014-0210-1

9. Cappell MS, Friedel D. Acute Nonvariceal Upper Gastrointestinal Bleeding: Endoscopic Diagnosis and Therapy. Medical Clinics of North America. 2008 May 1;92(3):511-50.

10. Hunter TB, Taljanovic MS. Foreign bodies. Radiographics: a review publication of the Radiological Society of North America, Inc [Internet]. 2003 [cited 2022 Jan 4];23(3):731-57. Available from: https://pubmed.ncbi.nlm.nih.gov/12740473/

11. Isa HMA, Hasan KA, Ahmed HY, Mohamed AM. Efficacy and Safety of Endoscopic Esophageal Dilatation in Pediatric Patients with Esophageal Strictures. International journal of pediatrics [Internet]. 2021 [cited 2022 Jan 4];2021. Available from:

https://pubmed.ncbi.nlm.nih.gov/34608394/

12. Siersema PD. Treatment options for esophageal strictures. Nature Clinical Practice Gastroenterology \& Hepatology 2008 5:3 [Internet]. 2008 Feb 5 [cited 2022 Jan 4];5(3):142-52. Available from: https://www.nature.com/articles/ncpgasthep1053

13. Ates F, Vaezi MF. The Pathogenesis and Management of Achalasia: Current Status and Future Directions. Gut and Liver [Internet]. 2015 Jul 1 [cited 2022 Jan 5];9(4):449. Available from: /pmc/articles/PMC4477988/

14. Fyock CJ, Draganov P v. Colonoscopic polypectomy and associated techniques. World Journal of Gastroenterology [Internet]. 2010 [cited 2022 Jan 4];16(29):3630-7. Available from: https://www.wjgnet.com/1007-9327/full/v16/i29/3630.htm

15. Schleinstein HP, Averbach M, Averbach P, Correa PAFP, Popoutchi P, Rossini LGB. ENDOSCOPIC BAND LIGATION FOR THE TREATMENT OF HEMORRHOIDAL DISEASE. Arquivos de gastroenterologia [Internet]. 2019 Jan 1 [cited 2022 Jan 5];56(1):22-7. Available from: https://pubmed.ncbi.nlm.nih.gov/31141063/

16. Chanie Y, Desalegn H, Conjeevaram H. Dr. The pattern and outcome of upper gastrointestinal bleeding at St. Paul's Millenium Medical College, Addis Ababa, Ethiopia. Ethiopian Medical Journal [Internet]. 2020 Sep 30 [cited 2022 Jan 4];58(04). Available from:

https://emjema.org/index.php/EMJ/article/view/1360

Page $7 / 12$ 
17. Taye M, Kassa E, Mengesha B, Gemechu T, Tsega E. Upper gastrointestinal endoscopy: a review of 10,000 cases. Ethiopian medical journal [Internet]. 2004 [cited 2022 Jan 10];42(2):97-107. Available from: https://pubmed.ncbi.nlm.nih.gov/16895026/

18. Solomon A. Woreta, Mensur O. Yassin, Solomon Y. Teklie, Gashaw M. Getahun, Zeki A. Abubeker. UPPER GASTROINTESTINAL ENDOSCOPY FINDINGS AT GONDAR UNIVERSITY HOSPITAL, NORTH-WESTERN ETHIOPIA: AN EIGHT YEAR ANALYSIS. International journal of pharmaceuticals and Health care Resarch [Internet]. 2015 [cited 2022 Jan 13];03(02):60-5. Available from: https://1library.net/document/zxl1 prnz-gastrointestinal-endoscopy-findings-university-hospital-western-ethiopia-analysis.html

19. Melese A, Genet C, Zeleke B, Andualem T. Helicobacter pylori infections in Ethiopia; Prevalence and associated factors: A systematic review and meta-analysis. BMC Gastroenterology [Internet]. 2019 Jan 10 [cited 2022 Jan 4];19(1):1-15. Available from: https://bmcgastroenterol.biomedcentral.com/articles/10.1186/s12876-018-0927-3

20. Shangavi Y, Rathod JB, Yagnik VD. A clinical study on etiology, prognosis, outcome and role of endoscopy in upper gastrointestinal bleed in a tertiary care center. Internet Journal of Medical Update - EJOURNAL [Internet]. 2018 Feb 23 [cited 2022 Jan 4];12(2):4-9. Available from: https://www.ajol.info/index.php/ijmu/article/view/167364

21. Jaka H, Koy M, Liwa A, Kabangila R, Mirambo M, Scheppach W, et al. A fibreoptic endoscopic study of upper gastrointestinal bleeding at Bugando Medical Centre in northwestern Tanzania: a retrospective review of 240 cases. BMC research notes [Internet]. 2012 [cited 2022 Jan 4];5. Available from: https://pubmed.ncbi.nlm.nih.gov/22537571/

22. Moledina SM, Komba E. Risk factors for mortality among patients admitted with upper gastrointestinal bleeding at a tertiary hospital: a prospective cohort study. BMC gastroenterology [Internet]. 2017 Dec 20 [cited 2022 Jan 4];17(1). Available from: https://pubmed.ncbi.nlm.nih.gov/29262794/

23. Mulima G, Qureshi JS, Shores C, Tamimi S, Klackenberg H, Andrén-Sandberg Å, et al. Upper Gastrointestinal Bleeding at a Public Referal Hospital in Malawi. Surgical Science [Internet]. 2014 Nov 6 [cited 2022 Jan 4];5(11):501-7. Available from: http://www.scirp.org/Html/22300800_51450.htm

24. Hernández-Díaz S, Rodríguez LAG. Incidence of serious upper gastrointestinal bleeding/perforation in the general population: review of epidemiologic studies. Journal of clinical epidemiology [Internet]. 2002 [cited 2022 Jan 4];55(2):157-63. Available from: https://pubmed.ncbi.nlm.nih.gov/11809354/

25. Surgical management of bleeding esopageal varices: the Tikur Anbessa hospital experience - PubMed [Internet]. [cited 2022 Jan 4]. Available from: https://pubmed.ncbi.nlm.nih.gov/16523647/

26. Waweru J, Ojuka D, Jani P, Kiraitu W, Onyango S, Okumu W. The Practice of Interventional Gastrointestinal Endoscopy at a Tertiary Referral Hospital. Annals of African Surgery [Internet]. 2018 May 11 [cited 2022 Jan 4];15(1). Available from: https://www.ajol.info/index.php/aas/article/view/170853

27. Hui AJ, Sung JJY. Endoscopic treatment of upper gastrointestinal bleeding. Current Treatment Options in Gastroenterology 2005 8:2 [Internet]. 2005 [cited 2022 Jan 4];8(2):153-62. Available from: https://link.springer.com/article/10.1007/s11938-005-0008-x

28. GO L, F M-F, SE M, FY H, E I, JM M, et al. Comparison between endoscopic sclerotherapy and band ligation for hemostasis of acute variceal bleeding. World journal of gastrointestinal endoscopy [Internet]. 2011 [cited 2022 Jan 4];3(5):95. Available from: https://pubmed.ncbi.nlm.nih.gov/21772940/

29. Schmitz RJ, Sharma P, Badr AS, Qamar MT, Weston AP. Incidence and management of esophageal stricture formation, ulcer bleeding, perforation, and massive hematoma formation from sclerotherapy versus band ligation. The American journal of gastroenterology [Internet]. 2001 Feb [cited 2022 Jan 4];96(2):437-41. Available from: https://pubmed.ncbi.nlm.nih.gov/11232687/

30. Wang J, Chen S, Naga YM, Liu J, Dai M, Yang S, et al. Esophageal variceal ligation monotherapy versus combined ligation and sclerotherapy for the treatment of esophageal varices. Canadian Journal of Gastroenterology and Hepatology. 2021;2021.

31. Czymek R, Großmann A, Roblick U, Schmidt A, Fischer F, Bruch HP, et al. Surgical management of acute upper gastrointestinal bleeding:still a major challenge. Hepato-gastroenterology [Internet]. 2012 May [cited 2022 Jan 4];59(115):768-73. Available from: https://pubmed.ncbi.nlm.nih.gov/22469719/

32. Lahbabi M, Elyousfi M, Aqodad N, Elabkari M, Mellouki I, Ibrahimi SA, et al. Esophageal variceal ligation for hemostasis of acute variceal bleeding: efficacy and safety. PAMJ 2013; 14:95 [Internet]. 2013 [cited 2022 Jan 4];14(95). Available from: https://www.panafrican-medjournal.com/content/article/14/95/full

33. Zauber AG, Winawer SJ, O’Brien MJ, Lansdorp-Vogelaar I, van Ballegooijen M, Hankey BF, et al. Colonoscopic Polypectomy and Long-Term Prevention of Colorectal-Cancer Deaths. New England Journal of Medicine [Internet]. 2012 Feb 23 [cited 2022 Jan 4];366(8):687-96. Available from: https://www.nejm.org/doi/full/10.1056/nejmoa1100370

34. Shaukat A, Mongin SJ, Geisser MS, Lederle FA, Bond JH, Mandel JS, et al. Long-term mortality after screening for colorectal cancer. The New England journal of medicine [Internet]. 2013 Sep 19 [cited 2022 Jan 4];369(12):1106-14. Available from: https://pubmed.ncbi.nlm.nih.gov/24047060/

35. Anderloni A, Jovani M, Hassan C, Repici A. Advances, problems, and complications of polypectomy. Clinical and experimental gastroenterology [Internet]. 2014 Aug 30 [cited 2022 Jan 4];7(1):285-96. Available from: https://pubmed.ncbi.nlm.nih.gov/25210470/

Page $8 / 12$ 
36. Kim JH, Shin JH, Song HY. Benign strictures of the esophagus and gastric outlet: interventional management. Korean journal of radiology [Internet]. 2010 Sep [cited 2022 Jan 4];11(5):497-506. Available from: https://pubmed.ncbi.nlm.nih.gov/20808692/

37. Mohamed MA, Mahmoud HS, Tag-Adeen M, Mohamed MA, Mahmoud HS, Tag-Adeen M. Treatment Modalities for Post Corrosive Esophageal Strictures: 5 Years Experience. Open Journal of Gastroenterology [Internet]. 2018 Nov 2 [cited 2022 Jan 4];8(11):394-404. Available from: http://www.scirp.org/journal/PaperInformation.aspx?PaperlD=88306

38. Tesfaye M, Ali A, Bekele A, Worku A. Pattern and treatment outcome of patients with achalasia cardia after Modified Heller's Myotomy: experience from Ethiopia. East and Central African Journal of Surgery [Internet]. 2016 Nov 14 [cited 2022 Jan 4];21(2):27-32. Available from: https://www.ajol.info/index.php/ecajs/article/view/147680

39. Mundre P, Black CJ, Mohammed N, Ford AC. Efficacy of surgical or endoscopic treatment of idiopathic achalasia: a systematic review and network meta-analysis. The Lancet Gastroenterology \& Hepatology. 2021 Jan 1;6(1):30-8.

40. Ponds FA, Fockens P, Lei A, Neuhaus H, Beyna T, Kandler J, et al. Effect of Peroral Endoscopic Myotomy vs Pneumatic Dilation on Symptom Severity and Treatment Outcomes Among Treatment-Naive Patients With Achalasia: A Randomized Clinical Trial. JAMA [Internet]. 2019 Jul 9 [cited 2022 Jan 4];322(2):134-44. Available from: https://pubmed.ncbi.nlm.nih.gov/31287522/

41. C S, H O, M T, CE L. Endoscopic management of foreign bodies in the upper gastrointestinal tract: A review. World journal of gastrointestinal endoscopy [Internet]. 2014 [cited 2022 Jan 4];6(10):475. Available from: https://pubmed.ncbi.nlm.nih.gov/25324918/

42. Brady PG, Johnson WF. Removal of foreign bodies: the flexible fiberoptic endoscope. Southern medical journal [Internet]. 1977 [cited 2022 Jan 4];70(6):702-4. Available from: https://pubmed.ncbi.nlm.nih.gov/877620/

43. Bane A, Bekele A. Management of Gastrointestinal Foreign bodies using Flexible Endoscopy: An experience from Addis Ababa, Ethiopia. East and Central African Journal of Surgery [Internet]. 2013 Jan 23 [cited 2022 Jan 10];17(3):32-8. Available from: https://www.ajol.info/index.php/ecajs/article/view/84813

44. Iwamuro M, Tanaka S, Shiode J, Imagawa A, Mizuno M, Fujiki S, et al. Clinical characteristics and treatment outcomes of nineteen Japanese patients with gastrointestinal bezoars. Internal medicine (Tokyo, Japan) [Internet]. 2014 [cited 2022 Jan 4];53(11):1099-105. Available from: https://pubmed.ncbi.nlm.nih.gov/24881731/

45. Gilyoma JM, Chalya PL. Endoscopic procedures for removal of foreign bodies of the aerodigestive tract: The Bugando Medical Centre experience. BMC ear, nose, and throat disorders [Internet]. 2011 [cited 2022 Jan 4];11(1). Available from: https://pubmed.ncbi.nlm.nih.gov/21255409/

46. Tadesse A, Feyo A. Management of Ingested Foreign Bodies in Paediatric Patients: An Experience from a Tertiary Hospital in Ethiopia. East and Central African Journal of Surgery [Internet]. 2014 [cited 2022 Jan 5];19(1):11-6. Available from: https://journal.cosecsa.org/index.php/ECAJS/article/view/669

47. Abiodun AA, Alatise OI, Okereke CE, Adesunkanmi ARK, Eletta EA, Gomna A. Comparative study of endoscopic band ligation versus injection sclerotherapy with $50 \%$ dextrose in water, in symptomatic internal haemorrhoids. The Nigerian postgraduate medical journal [Internet]. 2020 Jan 1 [cited 2022 Jan 5];27(1):13-20. Available from: https://pubmed.ncbi.nlm.nih.gov/32003357/

\section{Figures}

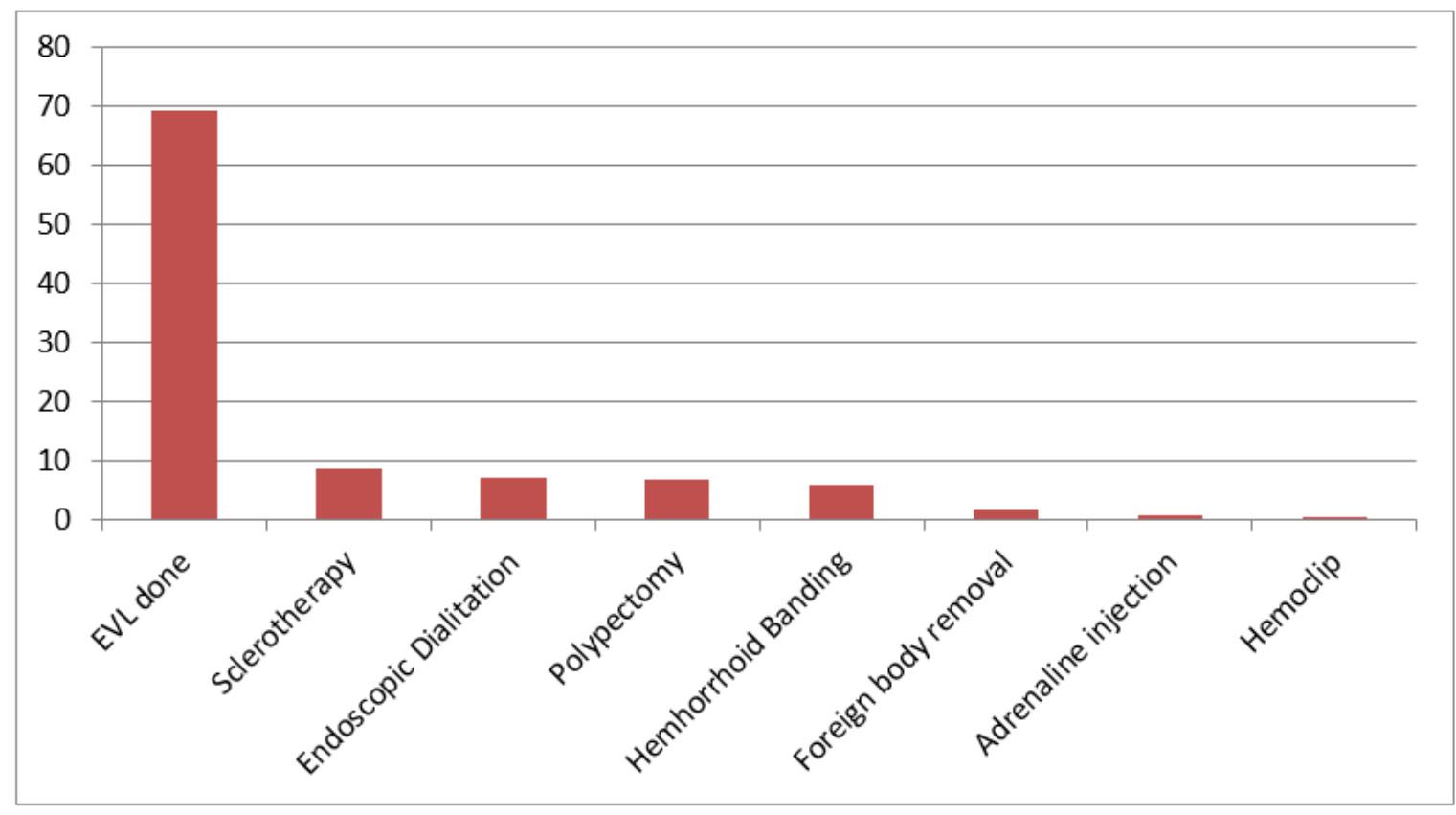

Page 9/12 


\section{Figure 1}

Percentage of interventional endoscopies that were performed at Adera Medical Center, Addis Ababa, Ethiopia from October 2013- September 2021

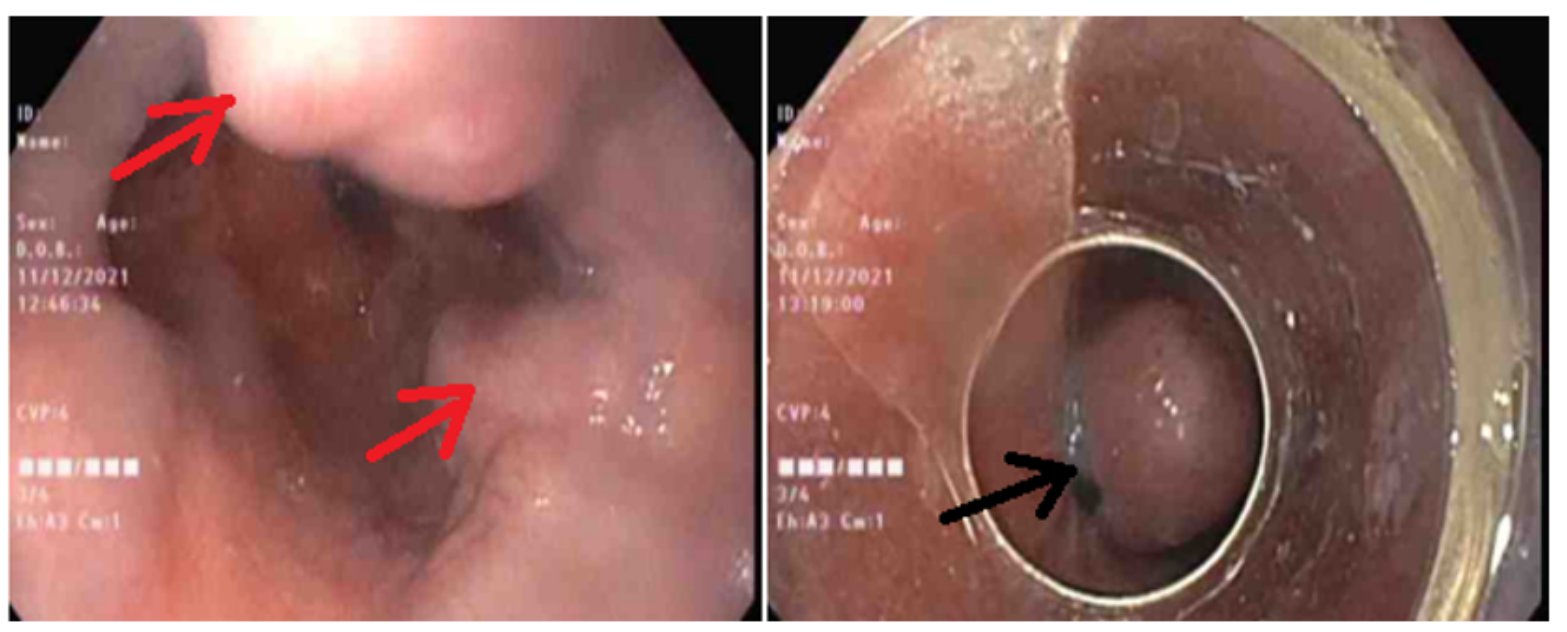

Figure 2

Endoscopic image of esophageal varices (left, red arrow) and image of the same varices after esophageal variceal band ligation (right, black arrow)

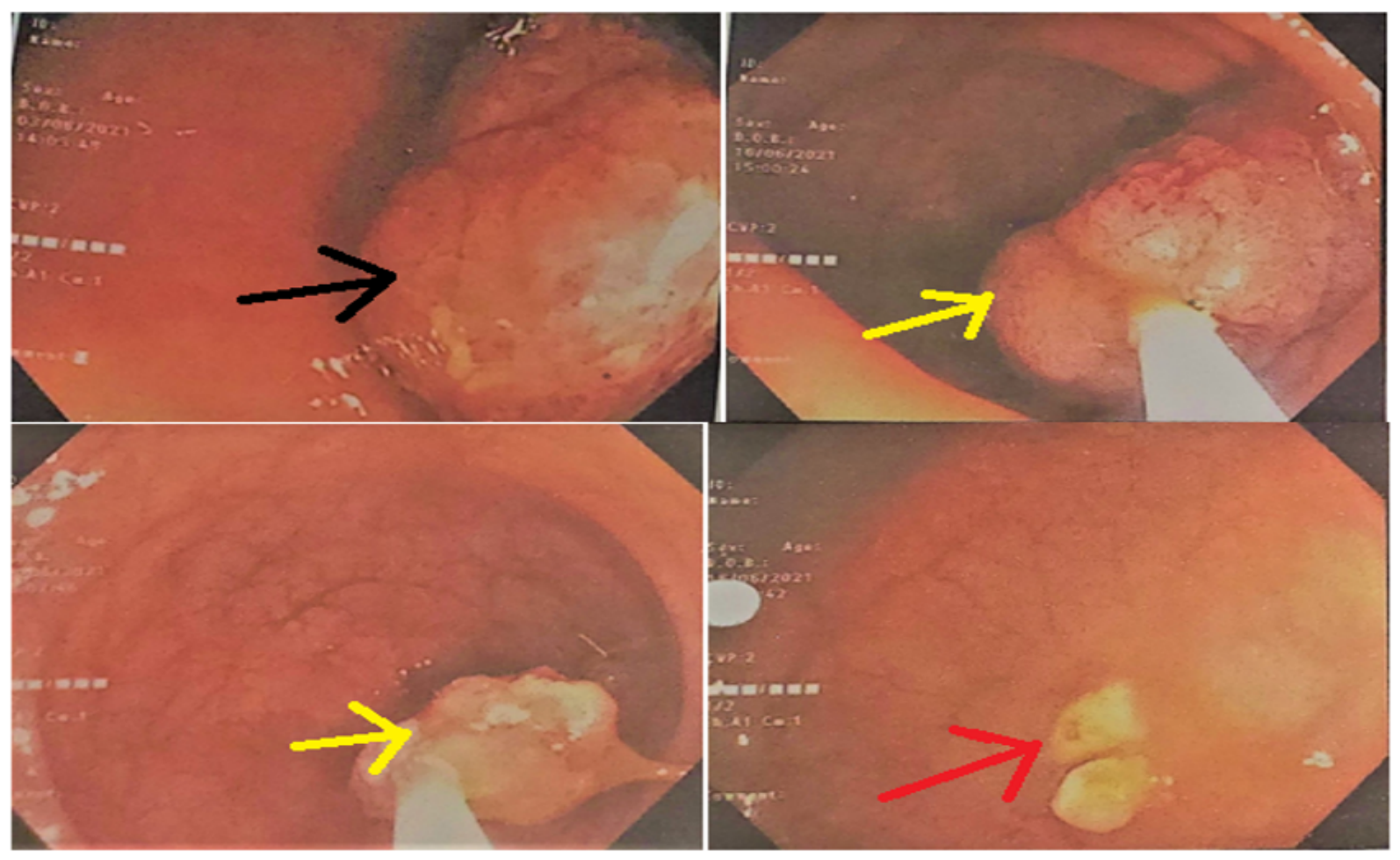

\section{Figure 3}

Endoscopic image of a colonic polyp (black arrow), the same polyp being resected (yellow arrow) and after it was endoscopically resected (red arrow) 


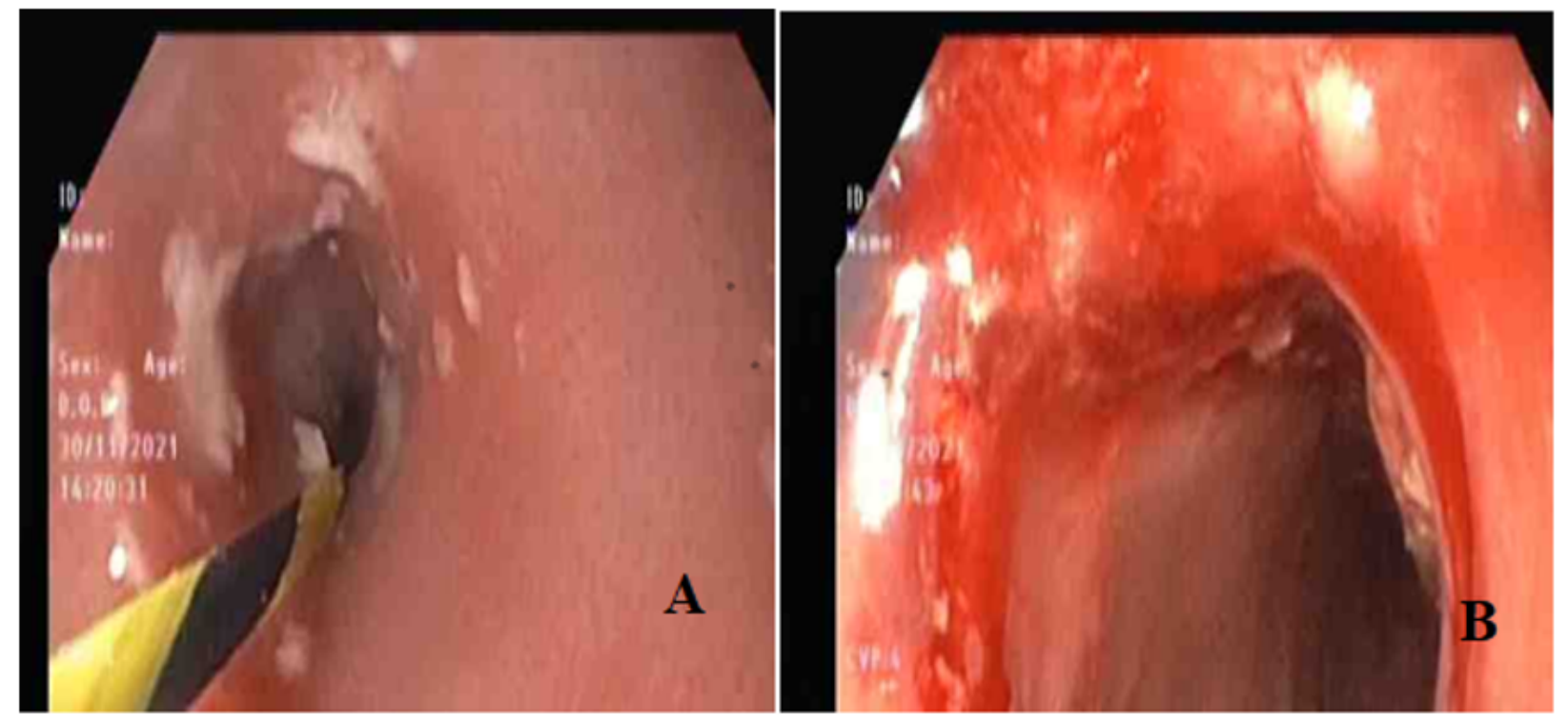

Figure 4

Benign esophageal stricture dilation using a bougie dilator in an Ethiopian Patient

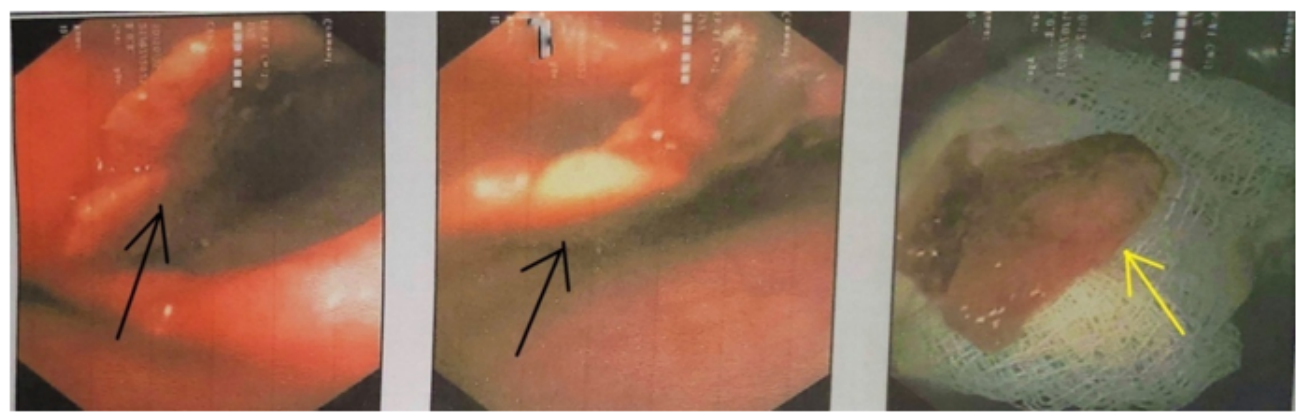

Figure 5

Endoscopic image of a bone piece in the esophagus (black arrows) and the bone after it is endoscopically extracted (yellow arrow) 


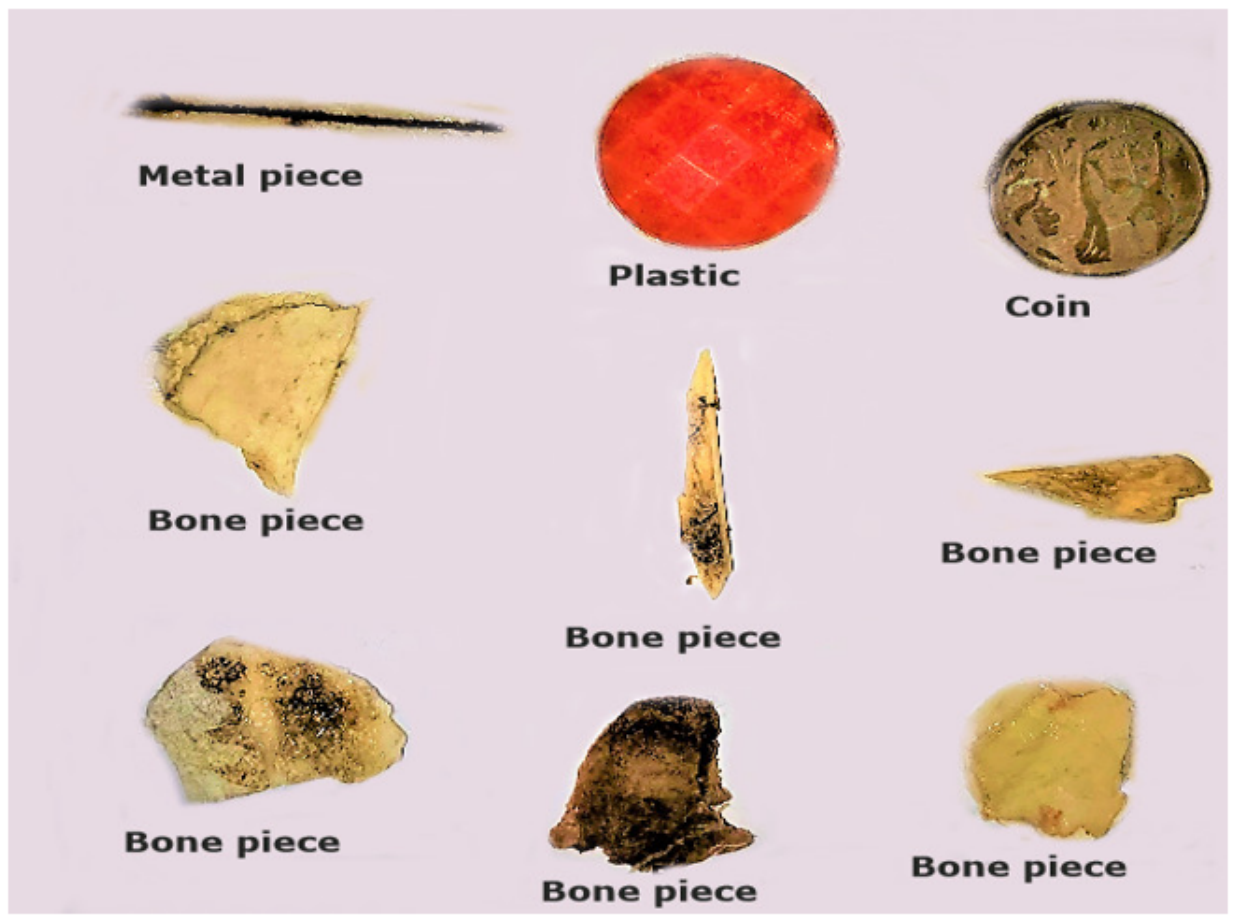

\section{Figure 6}

some of the oreign bodies (bone pieces, coin, sharp metal pieces, and plastic objects) endoscopically removed from patients' GIT at Adera medical center during the study peroid 